\title{
Internet Addiction Disorder among Adolescents' Students
}

\author{
*Samah Said Sabry *\&Amina Abdelrazek Mahmoud* \\ * Community Health Nursing, Faculty of Nursing, Benha University, Egypt.
}

\begin{abstract}
Background: The internet was originally designed to facilitate communication and research activities. However, the dramatic increase in the use of the internet in recent years has led to pathological use (Internet addiction disorder).The adolescent population is highly prone to internet addiction and this can affect their personal, family, academic, interpersonal and social life. The aim of this study was to evaluate the internet addiction disorder on adolescents' students. Research design: A Descriptive design was used in this study. Setting: The study was conducted at all secondary schools for girls at Benha City they named; Benha Secondary School, El Shimaa Secondary School, and Om Elmoamneen Secondary School. The sample included 200 secondary female students they were selected as systematic random sample from studied schools. Tools: A structured interviewing questionnaire consisted of five parts1) the socio-demographic characteristics, 2)the pattern of internet use, 3) diagnostic criteria of internet addiction among the students, 4) students' knowledge regarding internet addiction and 5) student's reported practices regarding internet addiction disorder. Results of this study showed; $42 \%$ of the students aged from 15 to less than 16 years old $(\mathrm{X} \pm \mathrm{SD}=15.62 \pm 1.12)$. As regard birth order $79 \%$ were the youngest, $48 \%$ of them in the third year of the study, and $75 \%$ live in urban area. $75 \%$ of the students were having the accessibility to internet at home, and $65 \%$ of them use the Internet every free time per day. Total knowledge scores of the secondary schools students regarding internet addiction disorder were good for only $31 \%$, and the total practices scores regarding internet addiction were satisfactory for only $26 \%$ of the students. This study concluded that: The internet addiction has a high negative impact among the students. Also there were high statistically significant relation between socio demographic characteristics of the students and their knowledge and practices regarding internet addiction disorder. The study recommended that: A similar study can be replicated on a large sample and a comparative study can be done with students of different groups of adolescents.
\end{abstract}

Key words: Internet Addiction disorder, Adolescents' Students \& Community Health Nurse others. These types of behavior put their

Introduction

The main risk to adolescents students online today are risks from each other, risks of improper use of technology, lack of privacy, sharing too much information, or posting false information about themselves or privacy at risk, when Internet users visit various Web sites, they can leave behind evidence of which sites they have visited. This collective, ongoing record of one's Web activity is called the "digital footprint." One of the biggest threats to young people on social media sites is to their digital footprint and future reputations. Preadolescents and 
adolescents who lack an awareness of privacy issues often post inappropriate messages, pictures, and videos without understanding that "what goes online stays online." As a result, future jobs and college acceptance may be put into jeopardy by inexperienced and rash clicks of the mouse. Indiscriminate Internet activity also can make adolescents easier for marketers and fraudsters to target (Barnes, 2010).

Internet addiction disorder (IAD), now more commonly called problematic Internet use (PIU), compulsive Internet use (CIU), Internet overuse, problematic computer use, or pathological computer use, refers to excessive computer use which interferes with daily life. Using internet becomes a risk to adolescents more often than most adults realize. Most risks fall into the following categories: peer-to-peer; inappropriate content; lack of understanding of online privacy issues; and outside influences of third-party advertising groups (Moreno et al., 2013).

Internet Addiction Disorder may present in both physical and emotional manifestations. Some of the emotional symptoms of Internet Addiction Disorder may include: depression, dishonesty, feelings of guilt, anxiety, feelings of euphoria when using the computer, inability to prioritize or keep schedules, isolation, no sense of time, defensiveness, avoidance of work, agitation, mood swings, fear, loneliness, boredom with routine tasks, and procrastination. Physical symptoms of internet addiction disorder may include: backache, carpal tunnel syndrome, headaches, insomnia, poor nutrition (failing to eat or eating in excessively to avoid being away from the computer), poor personal hygiene (e.g., not bathing to stay online), neck pain, dry eyes and other vision problem, or weight gain or loss (Gregory, 2016).

Community Health Nurses (CHN) are in a unique position to educate adolescent students about both the complexities of the digital world and the challenging social and health issues that online adolescent experience by encouraging adolescents to face the core issues of bullying, popularity and status, depression and social anxiety, risk-taking, and sexual development. CHN can help adolescents understand that what is happening online is an extension of these underlying issues and that adolescents can be most helpful if they understand the core issues and have strategies for dealing with them whether they take place online, offline, or increasingly, both (Lenhart, 2015).

Community Health Nurses play an important role by educating and increase awareness among the adolescent students about the benefits and dangers effect of technology addiction, Also Advise students to control their online use and the specific issues that today's online students face, also advise students to work on their own participation gap in their life day by becoming better educated about the many technologies there are using, CHN should discuss with students the need for online-use plan that involves regular meetings to discuss online topics and checks of privacy settings and online profiles for inappropriate posts. The emphasis should be on citizenship and healthy behavior and not punitive action, unless truly warranted (Christakis and Moreno, 2013).

\section{Significant of the study:}

Internet Addiction disorder is a serious condition that affects millions around the world, consider a mental disorder, especially among adolescence, and affect overall aspect of lifestyle, with time can be dangerous. This is the time to study and put a big spot on this phenomenon. This research may also help students to understand the impacts of the addiction to the tech-gadgets and services and make them aware of controlling the use of devices (Lenhar et al., 2010). 
In Egypt the internet usage is growing intensively. The number of internet users in Egypt increased by 28 percent during the year 2010. Egypt's internet and mobile phone usage rates 12 are among the highest in the developing world. More than 23 million Egyptians used the internet by the end of the year 2010, up from 16.6 million in 2009 (Aly, 2012).

\section{Aim of the Study:}

This study aimed to evaluate the internet addiction disorder on adolescents' students at Benha City through:-

*Assessing knowledge \& practices of the students through asking questions regarding internet addiction disorder.

*Assessing diagnostic criteria of internet addiction among the students.

\section{Research questions:}

To fulfill the aim of this study the following research questions formulated:

1- Is there an effect of internet addiction on adolescent's students' health?

2- The adolescent students have knowledge regarding internet addiction disorder?

3- Is there a relationship between sociodemographic characteristics of the adolescents' students and their knowledge and practices regarding internet addiction disorder?

Subjects and Methods

A - Research design:

- A descriptive research design was utilized to conduct the study.

\section{B- Setting:}

The study was conducted at all secondary schools for girls at Benha City, they named; Benha Secondary School, El Shimaa Secondary School, and Om Elmoamneen Secondary School.

\section{C-Sampling:}

The studied sample included 200 secondary female students they were selected as systematic random sample from the above mentioned setting as (every ten's student). The study sample was selected as follow:

\begin{tabular}{|l|r|r|}
\hline School Name & $\begin{array}{l}\text { Total } \\
\text { Number of } \\
\text { Students }\end{array}$ & $\begin{array}{l}\text { Number of } \\
\text { Selected } \\
\text { Students }\end{array}$ \\
\hline $\begin{array}{l}\text { Om } \\
\text { Elmoamneen } \\
\text { Secondary } \\
\text { School }\end{array}$ & $\begin{array}{r}900 \\
\text { students } \\
\text { students }\end{array}$ \\
\hline $\begin{array}{l}\text { ElShimaa } \\
\text { Secondary } \\
\text { School }\end{array}$ & 640 & 64 \\
\hline $\begin{array}{l}\text { Benha } \\
\text { Secondary } \\
\text { School }\end{array}$ & students & students \\
\hline
\end{tabular}

\section{D- Tools of data collection}

A structured interviewing questionnaire: It consisted of the following five parts:

Part one: Concerned with sociodemographic characteristics of the secondary schools students included five items as age, birth order, family members, grade of the study, and place of residence.

Part two: Concerned with the students use of internet included six items as availability of internet at home, mode of using internet, pattern of internet recharge per month in pound, duration of using internet 
per day, frequency of using the internet, and online-activities causing internet addiction. Scoring system; for each item was given as follows: 1if yes, and zero if no.

Part three: Designed to assess diagnostic criteria (negative impact) of internet addiction among the students which included (26) items divided into: 8 items about physical health problems, 5 items about academic problems, 2 items about social problems, 6 items about behavioral problems, and 5 items about psychological problem. Scoring system; for each item was given as follows: 1if yes, and zero if no. Total score $=26$

Part four: Designed to assess the students' knowledge about internet addiction which included (7) items divided into: 2 items about meaning of internet addiction, 3 items about positive impact of internet addiction, and 2 items about negative impact of internet addiction. Scoring system; for each question was given as follows: 2 if complete, 1 if incomplete and zero if don't know. The total knowledge scores were considered good if the score of the total knowledge $\geq 75 \%(\geq 5)$, considered average if it is equals $50-<75 \%(3-5)$, and considered poor if it is less than $50 \%(<3)$.

Part five: It consisted of two items:

The first item: Designed to assess the students' practices regarding internet use through asking questions which included 10 items asstay online longer than expected more and more often, ignore and avoid other work or activities to spend more time onscreen, often check messages or emails before doing something else need to do, even delaying meals, frequently get annoyed or irritable if someone bothers when trying to do something online or on the phone,.....etc. Scoring system; for each item was given as follows: 1if yes, and zero if no.

The second item: Designed to assess the students' practices regarding internet addiction treatment through asking questions, which included 7 items as practice the opposite (construct a new reduced schedule or time pattern for using the Internet), external stoppers (use concrete things such as time to work, or places to go, as prompters to help $\log$ off), setting goals (set clear and achievable goals to help develop new tangible internet use schedules, prevent cravings, withdrawal, and relapse; and give the addict a sense of control),......etc.

The total practices were considered satisfactory if the score of total practices equals $\geq 65 \%(\geq 4)$, and considered unsatisfactory if it is $<65 \%(<4)$.

\section{Validity test}

The tools were revised for content validity by 3 juries who were experts in the Community Health Nursing Specialties, for clarity, relevance, comprehensiveness, and applicability. According to their suggestions, the modifications were applied.

\section{Reliability test}

Reliability of the tools was applied by the researcher for testing the internal consistency of the tool, by administration of the same tools to the same subjects under similar condition on one or more occasion. Answers from repeated testing were compared (test- re -test reliability). $=(0.78)$

\section{Operational design}

\section{A- Preparatory phase:}

Preparation of the study design and data collection tools was based on reviewing current and past, local and international related literature about various aspects of internet addiction by using periodicals journal, magazines, books and computer search to construct the tool of the study.

\section{B- Legal aspect for ethical considerations:}


Oral consent was been obtained from each student before conducting the interview and given a brief orientation to the purpose of the study. They were also reassured that all information gathered would be confidential and used only for the purpose of the study. No names were required on the forms to ensure anonymity and confidentiality.

\section{C- Pilot study:}

A pilot study was conducted to assess tools clarity and applicability. It has also served in estimating the time needed for filling the form of the study. It has also served in determining the needs of students which have been taken in consideration during developing the health educational guideline. It represented $10 \%$ of the sample (20 students) they were included in the study sample.

\section{D- Field work:}

- Official letter from Faculty of Nursing - Benha University to the central agency of statistics and mobilization were prepared and delivered to the administration of education in Qualyobia. Permission from administration of education in Qualyobia was obtained to interviewing the students. Oral consent of the students was taken to participate in the study.

- Data were collected throughout the period from beginning of February 2016 till May 2016. The researcher visited the selected schools from 9 am - 1 pm, three days / week by rotation (Saturdays, Mondays and Tuesdays). The fieldwork was performed in the following sequence: In each school, study aim and importance was clarified to the head master and class teachers to gain their support and cooperation. In each class, the researcher explained the study purpose to the students. Questionnaire sheets were distributed to students in the class, and they were asked to fill them individually.
- A health educational guideline. It consisted three phases;

- Phase 1: assessment, collected data, and detect needs of the students.

- Phase 2: developing a health educational guideline according to needs of the students.

- Phase 3: content of guideline: included the following items: Meaning of internet addiction disorder, positive impact of internet addiction disorder, negative impact of internet addiction disorder, pattern of internet use, and practices regarding internet addiction treatment disorder.

\section{Statistical design}

The collected data were verified prior to computerized entry; statistical analysis was done by using the Statistical Package for Social Science (SPSS) version 20. Data were presented in tables by using mean, standard deviation, number, percentage distribution, and Chi- Square. Statistical significance was considered at:

$$
\begin{aligned}
& \text { P- Value }>0.05 \text { insignificant } \\
& \text { P- Value }<0.05 \text { significant } \\
& \text { P- Value }<0.001 \text { highly significant. }
\end{aligned}
$$

\section{Results}

Table (1) shows that; $42 \%$ of the students aged from 16 to less than 17 years old with mean and standard deviation $=15.62$ \pm 1.12 . As regard birth order $79 \%$ were the youngest, $40 \%$ had 5 to less than 7 of family members, $48 \%$ of them in the third year of the study, and $75 \%$ live in urban area.

Table (2) shows that; $90 \%$ of the students were having the availability to internet at home, $85 \%$ of them were using 
internet through mobile, $66 \%$ of them were recharging internet pack for 25 pound per month, $40 \%$ of them were browsing internet from 4 to 6 hours a day. As regard frequency of using the internet; $65 \%$ of them use the Internet every free time per day, and $78 \%$ of them using the internet for chatting.

Table (3a) shows that; $75 \%$ of the students reported that back pain as the main of physical health problem, followed by headache for $60 \%$ of them. As regard academic problems; $54 \%$ of the students reported that low performance is the more problem, followed by school absence is the second problem for $42 \%$ of them, while $78 \%$ of them reported that relationship problem with family members, friends, teachers, or others as the main problem of social problems, and $62 \%$ of them reported that sleep deprivation is the main problem of behavioral problems.

Table (3b) shows that; $48 \%$ of the students reported that; anxiety and short attention span respectively are the main psychological problem, followed by depression for $43 \%$ of them.

Table (4) shows that; $58 \%$ of the students had good knowledge about internet addiction meaning, while $65 \%$ of them had good knowledge about all positive impact of internet addiction, and $75 \%$ of them had good knowledge about all negative impact of internet addiction.

Figure (1): Illustrate that; total knowledge scores of the secondary schools students regarding internet addiction were good for $31 \%$ and poor for $41 \%$ of them.

Table (5): Explains the students' practices regarding internet use through asking questions. $82 \%$ of them prefer to spend time with people on-line or through messaging rather than being with them face to face, while $60 \%$ of them often check messages or emails before doing something else the students need to do, even delaying meals, and $58 \%$ of them frequently get annoyed or irritable if someone bothers when trying to do something online or on the phone.

Table (6): Demonstrates the students' practices through asking questions regarding internet addiction treatment; were $62 \%$ of the students practice the opposite (construct a new reduced schedule or time pattern for using the Internet), while $31 \%$ of them setting goals (set clear and achievable goals to help develop new tangible Internet use schedules, prevent cravings, withdrawal, and relapse; and give the addict a sense of control), and only $10 \%$ use external stoppers (use concrete things such as time to work, or places to go, as prompters to help log off).

Figure (2): Illustrates that; the total practices scores of the secondary school students regarding internet addiction were satisfactory for only $26 \%$ and unsatisfactory for $74 \%$ of them.

Table (7) Shows that; there were high statistically significant differences between the students' total knowledge scores and their age, birth order, family members, grade of study, and residence $(\mathrm{P}<0.001)$, while there were not statistically significant differences between the students' total practices scores and their gender $(\mathrm{P}>0.05)$.

Table (8) Shows that; there were high statistically significant differences between the students' total practices scores and their age, birth order, and their grade of study ( $\mathrm{P}<$ 0.001 , while there were not statistically significant differences between the students' total practices scores and their gender, family members, and their residence $(\mathrm{P}>0.05)$. 
Table (1): Distribution of secondary schools students according to their sociodemographic characteristics $(n=200)$.

\begin{tabular}{|c|c|c|}
\hline Socio-demographic characteristics & (No.) & $(\%)$ \\
\hline \multicolumn{3}{|l|}{ Age / years } \\
\hline $15-$ & 28 & 14.0 \\
\hline $16-$ & 84 & 42.0 \\
\hline $17-$ & 40 & 20.0 \\
\hline 18 years & 48 & 24.0 \\
\hline \multicolumn{3}{|c|}{$\mathbf{X} \pm \mathbf{S D}=15.62 \pm 1.12$} \\
\hline \multicolumn{3}{|l|}{ Birth order } \\
\hline The oldest & 38 & 19.0 \\
\hline The middle & 44 & 22.0 \\
\hline The youngest & 118 & 59.0 \\
\hline \multicolumn{3}{|l|}{ Family members } \\
\hline $3-$ & 68 & 34.0 \\
\hline $5-$ & 80 & 40.0 \\
\hline $7+$ & 52 & 26.0 \\
\hline \multicolumn{3}{|c|}{$\mathrm{X} \pm \mathrm{SD}=5.20 \pm 1.55$} \\
\hline \multicolumn{3}{|l|}{ Grade of the study } \\
\hline $1^{\text {st }}$ year & 96 & 48.0 \\
\hline $2^{\text {nd }}$ year & 54 & 27.0 \\
\hline $3^{\text {rd }}$ year & 50 & 25.0 \\
\hline \multicolumn{3}{|l|}{ Residence } \\
\hline Rural & 50 & 25.0 \\
\hline Urban & 150 & 75.0 \\
\hline
\end{tabular}


Table (2): Distribution of secondary schools students according to their internet use $(n=200)$.

\begin{tabular}{|c|c|c|}
\hline *Internet use & (No.) & $(\%)$ \\
\hline Availability of internet at home ( YES) & 180 & 90.00 \\
\hline \multicolumn{3}{|l|}{ Mode of using internet } \\
\hline Mobile & 170 & 85.0 \\
\hline I phone & 26 & 13.0 \\
\hline Laptop & 76 & 38.0 \\
\hline Computer & 54 & 27.0 \\
\hline Tablet & 50 & 25.0 \\
\hline \multicolumn{3}{|c|}{ Pattern of internet recharge pert month in pound } \\
\hline 10 & 28 & 14.0 \\
\hline 25 & 132 & 66.0 \\
\hline 50 & 60 & 30.0 \\
\hline$>50$ & 20 & 10.0 \\
\hline \multicolumn{3}{|l|}{ Duration of using internet per day } \\
\hline$<1$ hour & 10 & 5.0 \\
\hline $1-3$ hours & 50 & 25.0 \\
\hline 4-6 hours & 80 & 40.0 \\
\hline$>6$ hours & 60 & 30.0 \\
\hline \multicolumn{3}{|l|}{ Frequency of using the Internet } \\
\hline Use the Internet once/ everyday & 70 & 35.0 \\
\hline Use the Internet every free time per day & 130 & 65.0 \\
\hline \multicolumn{3}{|l|}{ Online-activities causing IA } \\
\hline Studying & 24 & 12.0 \\
\hline Calling & 120 & 60.0 \\
\hline Chatting & 156 & 78.0 \\
\hline Gaming & 140 & 70.0 \\
\hline Emailing & 40 & 20.0 \\
\hline Watching online-TV & 80 & 40.0 \\
\hline
\end{tabular}

N.B.* the answer not mutually exclusive. 
Table (3a): Distribution of the secondary schools students according to their diagnostic criteria (negative impact) of internet addiction $(n=200)$.

\begin{tabular}{|l|c|c|}
\hline \multicolumn{1}{|c|}{ *Diagnostic criteria (negative impact) of internet addiction } & No. & \% \\
\hline Physical health problems & 160 & 60.0 \\
\hline Headache. & 150 & 75.0 \\
\hline Back pain. & 112 & 56.0 \\
\hline Weight gain & 24 & 12.0 \\
\hline Weight loss & 16 & 8.0 \\
\hline Dehydration. & 54 & 27.0 \\
\hline Eye strain. & 60 & 30.0 \\
\hline Eye soreness. & 42 & 21.0 \\
\hline Hand corns. & & \\
\hline Academic problems & 84 & 42.0 \\
\hline School absences. & 70 & 35.0 \\
\hline Poor grades. & 112 & 56.0 \\
\hline Low performance & 24 & 12.0 \\
\hline Failing at school. & 38 & 19.0 \\
\hline Having difficulties when performing easy tasks. & & \\
\hline Social problems (n=130) & 78 & 78.0 \\
\hline Relationship problems with family members, friends, teachers, others. & 52 & 52.0 \\
\hline $\begin{array}{l}\text { Neglect other activities such as homework, sport, social activities due to } \\
\text { spending too much time online. }\end{array}$ & & \\
\hline Behavioral problems & 64 & 32.0 \\
\hline Acting aggressively. & 26 & 13.0 \\
\hline Yelling & 20 & 10.0 \\
\hline Swearing and unprovoked bad temper & 44 & 22.0 \\
\hline Isolation. & 124 & 62.0 \\
\hline Sleep deprivation. & 86 & 43.0 \\
\hline Skipping meals, exercise. & & \\
\hline & & \\
\hline
\end{tabular}

N.B. $*$ the answer not mutually exclusive. 
Table (3b): Distribution of the secondary schools students according to their diagnostic criteria of internet addiction $(n=200)$

\begin{tabular}{|l|c|c|}
\hline$*$ Diagnostic criteria of internet addiction & No. & \% \\
\hline Psychological problem & & \\
\hline Restlessness & 24 & 12.0 \\
\hline Anxiety & 116 & 58.0 \\
\hline Short attention span & 116 & 58.0 \\
\hline Depression & 86 & 43.0 \\
\hline Agitation & 16 & 8.0 \\
\hline
\end{tabular}

* N.B. the answer not mutually exclusive.

Table (4): Distribution of the secondary schools students according to their knowledge regarding internet addiction disorder $(n=200)$.

\begin{tabular}{|l|c|c|}
\hline \multicolumn{1}{|c|}{ *Knowledge } & No. & $\%$ \\
\hline Internet addiction disorder (IA) means: & & 85.0 \\
\hline $\begin{array}{l}\text { Psycho physiological disorder caused by an excessive, non- } \\
\text { essential use of the Internet that brings harm to the user or others } \\
\text { within the community. }\end{array}$ & 170 & 36.0 \\
\hline $\begin{array}{l}\text { Psychological, physical, social or other important functioning } \\
\text { impairments". }\end{array}$ & 72 & 58.0 \\
\hline All of them & 116 & 30.0 \\
\hline Don't know & 60 & 46.0 \\
\hline Positive impact of IAdisorder & 92 & 38.0 \\
\hline Sharing and collecting information. & 76 & 75.0 \\
\hline Searching for jobs. & 150 & 65.0 \\
\hline Communication and entertainment. & 130 & 6.0 \\
\hline All of them & 12 & 36.0 \\
\hline Don't know & & 68.0 \\
\hline Negative impact of IA disorder & 72 & 75.0 \\
\hline Health problems & 136 & 15.0 \\
\hline Relationship and social problems. & 30 & \\
\hline All of them & & \\
\hline Don't know & & \\
\hline
\end{tabular}

*N.B. the answer not mutually exclusive. 
Figure (1): Percentage distribution for total knowledge scores of the secondary schools students regarding internet addiction disorder $(n=200)$.

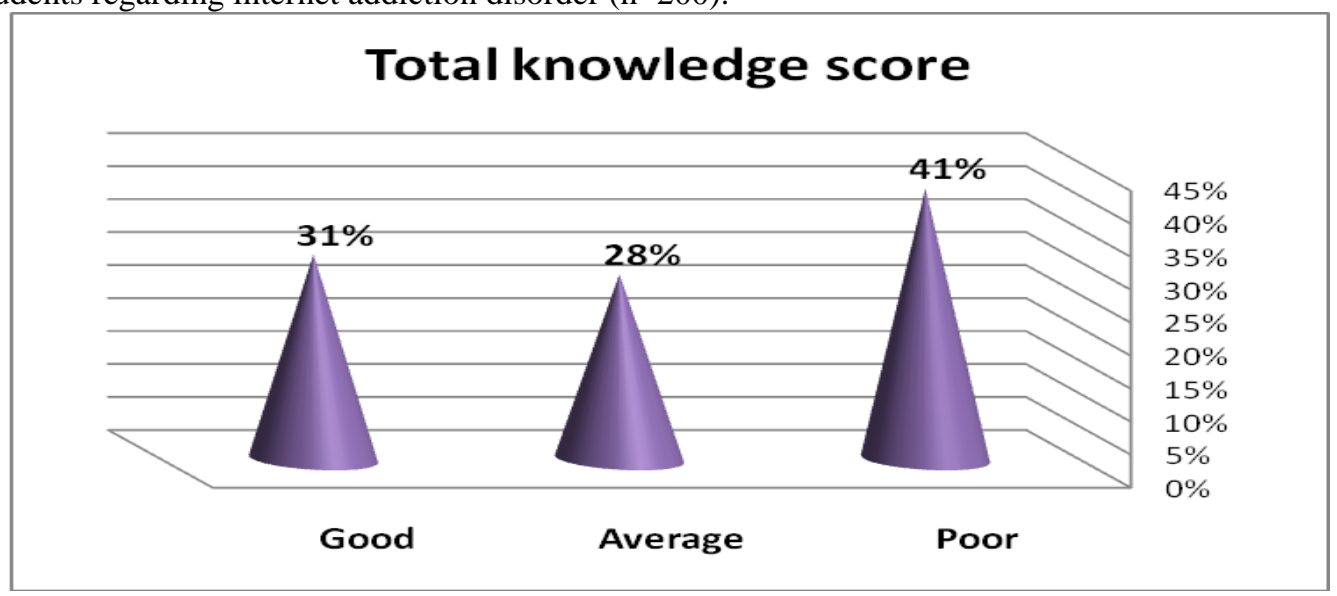

Table (5): Distribution of students according to their practices regarding internet use through asking questions $(\mathrm{n}=200)$.

\begin{tabular}{|l|c|c|}
\hline \multicolumn{1}{|c|}{$*$ Practice regarding internet use } & No. & \% \\
\hline Stay online longer than you expected more and more often. & 128 & 64.0 \\
\hline Ignore and avoid other work or activities to spend more time on-screen. & 124 & 60.0 \\
\hline $\begin{array}{l}\text { Often check messages or emails before doing something else need to do, even } \\
\text { delaying meals. }\end{array}$ & 120 & 58.0 \\
\hline $\begin{array}{l}\text { Frequently get annoyed or irritable if someone bothers when trying to do } \\
\text { something online or on the phone. }\end{array}$ & 116 & 82.0 \\
\hline $\begin{array}{l}\text { Prefer to spend time with people on-line or through messaging rather than being } \\
\text { with them face to face. }\end{array}$ & 164 & 80.0 \\
\hline $\begin{array}{l}\text { Think a lot about when you can get back online when you are off-line } \\
\text { Argue with, or feel criticized by friends, partners or family about the amount of } \\
\text { time you spend online. }\end{array}$ & 158 & 79.0 \\
\hline $\begin{array}{l}\text { Get excited, both anticipating when you can next get online, and also thinking } \\
\text { about what you will do }\end{array}$ & 124 & 62.0 \\
\hline Prefer on-screen activities now to going out and doing something else. & 144 & 72.0 \\
\hline Hide, or become defensive about what you do online. & 138 & 69.0 \\
\hline
\end{tabular}

*N.B. the answer not mutually exclusive. 
Table (6): Distribution of the secondary schools students according to their practices through asking questions regarding internet addiction disorder treatment $(n=200)$.

\begin{tabular}{|c|c|c|}
\hline *Internet addiction disorder treatment & No. & $\%$ \\
\hline $\begin{array}{l}\text { Practice the opposite (construct a new reduced schedule, time pattern for } \\
\text { using the Internet). }\end{array}$ & 124 & 62.0 \\
\hline $\begin{array}{l}\text { External stoppers (use concrete things such as time to work, places to go, as } \\
\text { prompters to help log off). }\end{array}$ & 20 & 10.0 \\
\hline $\begin{array}{l}\text { Setting goals (set clear and achievable goals to help develop new tangible } \\
\text { Internet use schedules, prevent cravings, withdrawal, relapse; and give the } \\
\text { addict a sense of control). }\end{array}$ & 62 & 31.0 \\
\hline $\begin{array}{l}\text { Reminder cards (use tangible, portable reminders of what addicts want to } \\
\text { avoid and what they want to do). }\end{array}$ & 26 & 13.0 \\
\hline $\begin{array}{l}\text { Personal inventory (generate a list of every activity or practice that has been } \\
\text { neglected, curtailed since the online habit emerged). }\end{array}$ & 24 & 12.0 \\
\hline $\begin{array}{l}\text { Social support (organize support groups tailored to addicts }{ }^{\text {ee }} \text { particular life } \\
\text { situations to decrease their dependence on online cohorts). }\end{array}$ & 26 & 13.0 \\
\hline $\begin{array}{l}\text { Family therapy focusing on moderation and controlled use (arrange therapy } \\
\text { for addicts who have marriages and family relationships). }\end{array}$ & 118 & 59.0 \\
\hline
\end{tabular}

* N.B. the answer not mutually exclusive.

Figure (2): The total practices scores of the secondary schools students regarding internet addiction disorder $(n=200)$.

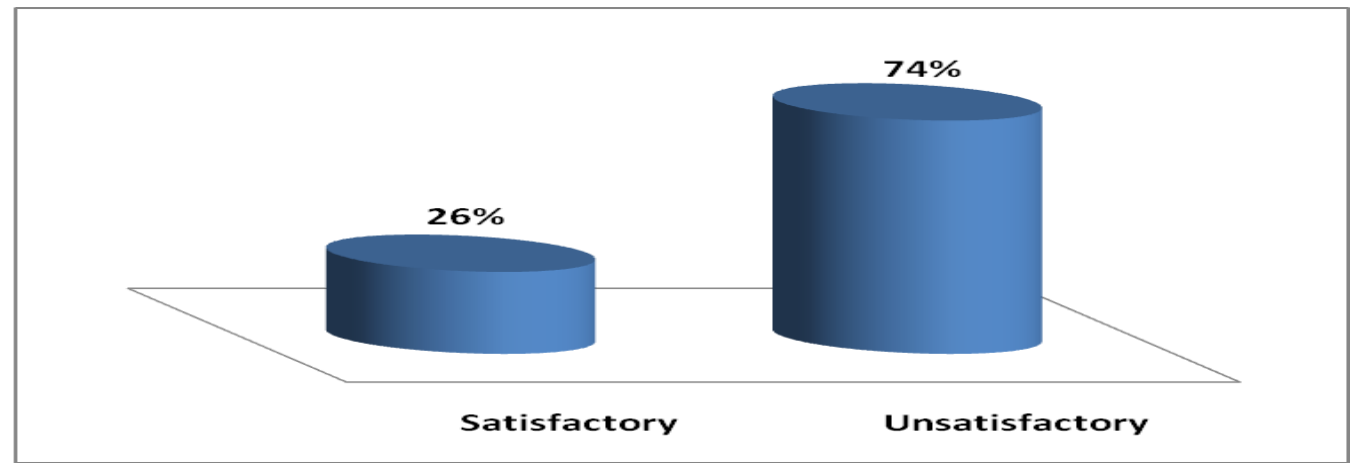


Table (7): Relations between the secondary schools' students' total knowledge scores \& their socio-demographic characteristics $(n=200)$.

\begin{tabular}{|c|c|c|c|c|c|c|c|c|}
\hline \multirow[t]{3}{*}{ Socio-demographic Characteristics } & \multicolumn{6}{|c|}{ Total knowledge } & \multicolumn{2}{|c|}{ Chi-Square } \\
\hline & \multicolumn{2}{|c|}{ Good } & \multicolumn{2}{|c|}{ Average } & \multicolumn{2}{|c|}{ Poor } & \multirow[t]{2}{*}{$\mathbf{X}^{2}$} & \multirow[t]{2}{*}{ P-value } \\
\hline & No. & $\%$ & No. & $\%$ & No. & $\%$ & & \\
\hline \multicolumn{7}{|l|}{ Age / years } & \multirow[t]{5}{*}{45.79} & \multirow[t]{5}{*}{$* *<0.001$} \\
\hline $15-$ & 6 & 21.4 & 0 & 0.0 & 22 & 78.6 & & \\
\hline $16-$ & 22 & 26.2 & 40 & 47.6 & 22 & 26.2 & & \\
\hline $17-$ & 4 & 10.0 & 12 & 30.0 & 24 & 60.0 & & \\
\hline 18 years & 34 & 70.8 & 4 & 8.4 & 10 & 20.8 & & \\
\hline \multicolumn{7}{|l|}{ Birth order } & \multirow[t]{4}{*}{38.95} & \multirow[t]{4}{*}{$* *<0.001$} \\
\hline The oldest & 22 & 57.9 & 0 & 0.0 & 16 & 42.1 & & \\
\hline The middle & 30 & 68.1 & 6 & 13.6 & 8 & 18.2 & & \\
\hline The youngest & 10 & 8.5 & 50 & 42.3 & 58 & 49.2 & & \\
\hline \multicolumn{7}{|l|}{ Family members } & \multirow[t]{4}{*}{23.30} & \multirow[t]{4}{*}{$* *<0.001$} \\
\hline $3-$ & 6 & 8.8 & 26 & 38.2 & 36 & 52.9 & & \\
\hline 5- & 22 & 27.5 & 26 & 32.5 & 32 & 40.0 & & \\
\hline $7+$ & 34 & 65.4 & 4 & 7.7 & 14 & 26.9 & & \\
\hline \multicolumn{7}{|l|}{ Grade of study } & \multirow[t]{4}{*}{16.90} & \multirow[t]{4}{*}{$* *<0.001$} \\
\hline $1^{\text {st }}$ year & 24 & 25.0 & 20 & 20.8 & 52 & 54.2 & & \\
\hline $2^{\text {nd }}$ year & 15 & 27.8 & 22 & 40.7 & 17 & 31.5 & & \\
\hline $3^{\text {rd }}$ year & 8 & 16.0 & 24 & 48.0 & 18 & 36.0 & & \\
\hline \multicolumn{7}{|l|}{ Residence } & \multirow[t]{3}{*}{24.35} & \multirow[t]{3}{*}{$* *<0.001$} \\
\hline Rural & 6 & 12.0 & 18 & 36.0 & 26 & 52.0 & & \\
\hline Urban & 56 & 37.3 & 38 & 25.3 & 56 & 37.3 & & \\
\hline
\end{tabular}


Table (8): Relations between the secondary schools' students' total practices scores \& their socio-demographic characteristics $(n=200)$.

\begin{tabular}{|c|c|c|c|c|c|c|}
\hline \multirow[t]{3}{*}{ Socio-demographic Characteristics } & \multicolumn{4}{|c|}{ Total practices } & \multicolumn{2}{|c|}{ Chi-Square } \\
\hline & \multicolumn{2}{|c|}{ Satisfactory } & \multicolumn{2}{|c|}{ Unsatisfactory } & \multirow[t]{2}{*}{$\mathrm{X}^{2}$} & \multirow[t]{2}{*}{ P-value } \\
\hline & No. & $\%$ & No. & $\%$ & & \\
\hline \multicolumn{5}{|l|}{ Age / years } & \multirow[t]{5}{*}{19.32} & \multirow[t]{5}{*}{$* *<0.001$} \\
\hline $15-$ & 0 & 0.00 & 28 & 100.0 & & \\
\hline $16-$ & 30 & 35.7 & 54 & 64.3 & & \\
\hline $17-$ & 2 & 5.0 & 38 & 95.0 & & \\
\hline 18 years & 20 & 41.6 & 28 & 58.3 & & \\
\hline \multicolumn{5}{|l|}{ Birth order } & \multirow[t]{4}{*}{13.9} & \multirow[t]{4}{*}{$* *<0.001$} \\
\hline The oldest & 0 & 0.0 & 38 & 100.0 & & \\
\hline The middle & 11 & 45.9 & 13 & 54.1 & & \\
\hline The youngest & 34 & 28.8 & 84 & 71.2 & & \\
\hline \multicolumn{5}{|l|}{ Family members } & \multirow[t]{4}{*}{4.39} & \multirow[t]{4}{*}{$>0.05$} \\
\hline 3- & 10 & 14.7 & 58 & 85.3 & & \\
\hline $5-$ & 22 & 27.5 & 58 & 72.5 & & \\
\hline $7+$ & 20 & 38.5 & 32 & 61.5 & & \\
\hline \multicolumn{5}{|l|}{ Grade of study } & \multirow[t]{4}{*}{15.62} & \multirow[t]{4}{*}{$* *<0.001$} \\
\hline $1^{\text {st }}$ year & 16 & 16.6 & 80 & 83.3 & & \\
\hline $2^{\text {nd }}$ year & 8 & 14.8 & 46 & 85.2 & & \\
\hline $3^{\text {rd }}$ year & 28 & 56.0 & 22 & 44.0 & & \\
\hline \multicolumn{5}{|l|}{ Residence } & \multirow[t]{3}{*}{0.64} & \multirow[t]{3}{*}{$>0.05$} \\
\hline Rural & 10 & 20.0 & 40 & 80.0 & & \\
\hline Urban & 42 & 28.0 & 108 & 72.0 & & \\
\hline
\end{tabular}

\section{Discussion}

Internet addiction (IA) is a relatively new field of academic inquiry. Empirical studies suggest that IA, like other well researched addictive behaviors, has an effect on many aspects of a person's life, including academic/work performance, relationships, physical and mental health. Evidence of IA has been suggested by the findings that some
Internet users spend increasingly longer Periods of time online and experience withdrawal symptoms when offline. Those Preoccupied with Internet-related activities may neglect exercise, family and social activities (Kim et al., 2010; Nalwa \& Anand, 2003; Seo, Kang, \& Yom, 2009; Yang\& Tung, 2007). 
Regarding socio-demographic characteristics of the students less than half of the students aged from 15 to less than 16 years old $(\mathrm{X} \pm \mathrm{SD}=15.62 \pm 1.12)$. This result was in harmony with study conducted by Aly (2012), who founded that less than half of the students aged from 15 to less than 16 years old. In the same context Kesaraporn Wanajak(2011), stated that about half of addictive Internet users were found to be in the group of students aged 15years old. This might be age seems to be a factor predicting IA, indicating that younger Internet users.

Regarding the gender the present study shows that, more than two third of studied sample were female. The finding is disagree with Kesaraporn Wanajak(2011), reported that the approximately half being male. This result was in harmony with study conducted by Alfred (2014), reported the opposite gender effect: that females became Internet dependent more often than males. However, this finding could be a result of the fact that $60 \%$ of young respondents were female Internet users.

The present study revealed that, three quarters of the studied sample were having the accessibility to internet at home, majority of them were using internet through mobile, more than two third of studied sample were recharging internet pack for 25 pound per month. This finding in disagreement with Rideout et al., (2010) reported that only forth of studied sample were having the accessibility to internet at home, only $20 \%$ of them were using internet through mobile. While this finding in agreement with Chacko etal., (2015) reported that, majority of studied sample were having the accessibility to internet at home, and more than two third of studied sample were recharging internet pack for less than 150 pound per month.

Regarding duration and frequency of using internet per day, more than one third of them were browsing internet from 4 to 6 hours a day. As regard frequency of using the internet; two thirds of them use the Internet every free time, and more than three quarters of them using the internet for chatting. This result was in harmony with study conducted by Aly, (2012) who founded that, the most of the students were browsing internet from 3-5 hours daily and use the Internet every free time. According to Department of Health (2008), The GSHS has been applied in 43 countries to date including Thailand, in the secondary schools surveyed, the findings show that more than one third of students spent three or more hours per day doing activities such as watching television, playing computer games, or talking on the telephone during a typical or usual day. Furthermore, People around the world can now quickly communicate with each other through the Internet using a range of applications: chatting, video conferencing, email, and Internet telephone. The Internet also provides different types of entertainment. Internet users can play games with other people in any part of the world, watch movies and 35listen to music. Internet users can form new relationships on the Internet (Internet World Stats, 2010).

The current study revealed that, diagnostic criteria or negative impact of internet addiction, three quarters of the students reported that back pain as the main of physical health problem, followed by headache for less than two thirds of them. According to Seo et al., (2009) reported that excessive use of computers and the Internet was related to headache, neck, shoulder and lower back pain. This might be beside the benefits of Internet use; negative impacts of its use have also been identified, including: impaired academic performance, health problems, personal relationship problems and social dysfunction.

As regard academic problems; more than half of the students reported that low performance is the more problem, followed by school absence is the second problem for less than half of them, while more than three 
quarters of them reported that relationship problem with family members, friends, teachers, or others as the main problem of social problems, and around two thirds of them reported that sleep deprivation is the main problem of behavioral problems. According to Ng \& Wiemer-Hastings, (2015); Punamäki et al., (2016) They found that, excessive Internet use was associated with sleep deprivation, the mental health and wellness impacts caused by IA were also identified, including preoccupation with Internet use, aggressive behavior, reduced learning ability and low performance, social alienation, loss of relationships, and altered sexual behavior in the three quarters of the students.

The results of present study has revealed that, slightly less than half of the students reported that; anxiety and short attention span respectively are the main problems of psychological problem, followed by depression for less than half of them. These results in the same line with Kesaraporn Wanajak (2011) reported having symptoms of mental illness, such as irritated, depression and anxious in half of the students. According to Van Rooijet al., (2010) depression, anxiety, and low self-esteem have been associated with excessive online gaming in adolescents between the ages of 13 and 16 . Correlation between depression and Internet addiction was also observed in slightly less than half of the Turkish high school students (Üneri \& Tanidir, 2011)

Regarding the students' total knowledge scores of the secondary schools students regarding technology addiction were good for one third of study sample and poor for less than half of study sample. This result was disagreement with study conducted by Chacko et al., (2015), who founded that, students' total knowledge scores of the secondary schools students regarding technology addiction were good for more than two thirds of study sample and poor for less than one third of study sample. This could be due to that internet addiction can be a threat to adolescent's health and social wellbeing. If the adolescent has adequate knowledge, it will enable them to use the internet wisely.

According the practices of the study regarding internet use through asking questions. The majority of them prefer to spend time with people on-line or through messaging rather than being with them face to face, this result in harmony with study conducted by Lenhart etal., (2007) who founded that, less than half of studied sample prefer to spend time with people on-line teens have uploaded pictures where others can see them. While in agreement with Lebo, (2013) who founded that, the majority of them prefer to spend time with people on-line or through messaging. According to Buckner etal.,(2012) some students choose to escape from stress by becoming immersed in cyberspace, those who lack confidence in social interaction offline tend to escape in online interaction. In addition, Rosen (2012) who founded that, the majority of them prefer to spend time with people on-line or through messaging argues that narcissists may also be driven to overuse the Internet to share every detail of their lives with a wide audience. Might be conversely, personality traits such as extroversion and high emotional stability are negatively correlated with Internet addiction.

The results of present study has revealed that, about two thirds of studied sample often check messages or emails before doing something else student needed to do, even delaying meals, This finding in agreement with National Coalition to Prevent Child Sexual Abuse and Exploitation (2013), who founded that, about two thirds of all teens exchange text messages every day with people in their lives far surpassing all other forms of daily communication including email, instant messaging, social networking and phone calling. In the same context Kesaraporn Wanajak(2011) stated that, more than two thirds studied sample often check messages or emails before doing 
something else student needed to do, even delaying meals.

The results of present study has revealed that, more than half of them frequently get annoyed or irritable if someone bothers when trying to do something online or on the phone. The finding is disagree with Kesaraporn Wanajak (2011) reported that; respondents were asked if they use the internet in the presence of a companion (defined as anyone including a friend, parent, sibling, teacher, or other internet users as in an Internet café) more than half of respondents indicated that they had company while using the Internet. The students identified the majority of the company when on the computer as friends in more than half of respondents, followed by brother/sister/sibling in more than one third, mother, and the father in only forth of students, the results show that there was no difference in IA between students who use the internet alone compared with students who use the Internet with a companion (4.2\% and $3.1 \%$, respectively). According to Park et al., (2008) this finding differed from those of the literature, this may be explained by the fact that the types of companions which had an effect on IA were friends but not parents. Thus, impacts of using internet with friends may differ when using the internet supervised by parents. This might be parental supervision contributed to the protection of children safety and the reduction of risky behaviors associated with Internet use.

The results of present study demonstrates that the students' practices through asking questions regarding internet addiction treatment; where about two thirds of the students practice the opposite (construct a new reduced schedule or time pattern for using the Internet), while about one third of them setting goals (set clear and achievable goals to help develop new tangible Internet use schedules, prevent cravings, withdrawal, and relapse; and give the addict a sense of control), and only tenth of them use external stoppers (use concrete things such as time to work, or places to go, as prompters to help log off). , this result was in harmony with study conducted by Kesaraporn Wanajak(2011) who founded that, several strategies were suggested including: participating in other creative activities $(9.61 \%)$; reducing the time spent on the Internet (6.79\%); and limiting the activities of Internet use (6.27\%).

The results of present study demonstrates that the total practices scores of the secondary school students regarding technology addiction were satisfactory for only one fourth of studied sample and unsatisfactory for about three quarters of them. This result was in harmony with study conducted by Yang \& Tung (2007), founded that, total practices scores of the secondary school students regarding technology addiction were satisfactory for only one third of studied sample and unsatisfactory for about two thirds of them.

The results of present study has revealed that, there were high statistically significant differences between the students' total knowledge scores and their age, birth order, family members, grade of study, and residence $(\mathrm{P}<0.001)$, The finding is agree with Ride out (2012): reported that statistically significant differences between the students' total knowledge scores and their age, birth order, family members, grade of study, and residence. Also, this finding in agreement with Chacko et al., (2015) who founded that the study there was a significant association between knowledge and selected demographic variables.

There were high statistically significant differences between the students' total practices scores and their age, birth order, and their grade of study $(\mathrm{P}<0.001)$, While there were not statistically significant differences between the students' total practices scores and their gender, family members, and their residence $(\mathrm{P}>0.05)$. The findings agree with 
Keeffe \& Pearson (2014) reported that not statistically significant differences between the students' total practices scores and their gender, family members, and their residence. While the finding is disagree with Aly, (2012) who founded that, statistically significant differences between the students' total practices scores and their gender, family members, and their residence $(\mathrm{P}>0.05)$

\section{Conclusion}

The internet addiction has a high impact on the student's health. Also the students had poor knowledge for the most of them, and high percent of them had poor practices regarding internet addiction prevention. There were high statistically significant relation between socio demographic characteristics of the students and their knowledge and practices regarding internet addiction.

\section{Recommendation}

The study recommended that:

- Educational program for students in schools about the positive and negative effect of internet use.

- Further research is needed for the prevention of internet addiction among adolescents and needs to examine the relative contribution each type of online activity may have on IA. Also A similar study can be replicated on a large sample and a comparative study can be done with students of different groups of adolescents.

\section{References}

Alfred D. (2014): Correlates of internet addiction among adolescents. Online journal http://www.scirp.org/journal/psych, 5, 1999-2008.
Aly H. (2012): The effect of technology on human behavior (a case study on BBC secondary school and the British University in Egypt). Faculty of Economics and Political Science, Cairo University, Department of Statistics.Pp.11, 12.

Barnes S. (2010): A privacy paradox: social networking in the United States. 11(9). Available at: http://firstmonday.org/htbin/cgiwrap/bin/o js/index. $\quad \mathrm{php} / \mathrm{fm} /$ article/ view/1394/1312.Accessed July 16, 2016.

Buckner J., Castille C., \& Sheets T. (2012): The five factor model of personality and employees' excessive use of technology. Computers in Human Behavior, 28 (5), 1947-1953.

Chacko H., Joseph J., Abraham J., Aranha P., and Shetty A. (2015):Ill effect of internet addiction knowledge and attitude among nursing students, Department of Child health Nursing, Yenepoya Nursing College, Mangaluru, INDIA. International Science Congress Association, Research Journal of Computer and Information Technology Sciences ISSN 2320 - 6527 Vol. 3(4), 14, Res. J. Computer and IT Sci.Available online at: www.isca.in.

Christakis D., \& Moreno M. (2013):Trapped in the net: will internet addiction become a 21st-century epidemic? Arch Pediatr Adolesc Med;163(10):959-960

Department of Health. (2008): The Global School-based Student Health Survey (GSHS), in Thailand, Bangkok. P.77.

Gregory CH. (2016): Internet Addiction Disorder. http://www.psycom. net/ iadcriteria.html. Accessed on 18 March2016. 
Hakala P., Rimpelä A,. Saarni L., \& Salminen J. (2006): Frequent computerrelated activities increase the risk of neckshoulder and low back pain in adolescents European Journal of Public Health, 16(5), 536-541.

Internet World State. (2010): Internet Usage Statistics: The Internet big picture: World Internet users and population stats. Available at: http:www. Internet world stats.com/stats.

Keeffe G., \&Pearson K. (2014):The Impact of Social Media on Children, Adolescents, and families. Pediatric Adolescent Med, 127 (4).P.89.

Kesaraporn W. (2011): Internet use and its impact on secondary school students in Chiangmal, Thall and, Thesis for Doctoral Degree in Philosophy, BNS MSc (Pharmacology) Faculty of Computing, Health and Science, Edith Cowan University, P.35.

Kim J., Hui H., Lau C., Kan P., Cheuk K., \& Griffiths M. (2010):Brief repPredictors of heavy Internet use and associations with health promoting and health risk behaviors among Hong Kong university students. Journal of Adolescence, 33(1), 215-220.

Lebo H. (2013): Surveying the Digital Future: Year Eleven, Center for the Digital Future USC Annenberg School for Communication and Journalism. Teens, smart phones \& texting. Washington, D.C.: Pew Research Center's Internet \& American Life Project.http://www.pewinternet.org/ /med ia//Files/Reports/2012/PIP_Teens_Smartp hones_and_Texting.pdf.

Lenhart A, Purcell K, Smith A \& Zickur K. (2010):Social Media and Young Adults. Washington, DC: Pew Research Center. Available at: http://pewinternet. org/
Reports/2010/Social-Media-and-YoungAdult aspx. Accessed May 3, 2016.

Lenhart A. (2015): Teens and Sexting. Washington, DC: Pew Research Center; Available

at: http://pewinternet.org/Reports/2009/Teen s-and-Sexting.aspx. Accessed January 4, 2016.

Moreno M., Jelenchick L., \& Christakis D. (2013): Problematic internet use among older adolescents: A conceptual framework". Computers and Human Behavior 29: 1879-1887.

Nalwa K., \& Anand, A. (2003). Internet Addiction in Students: A Cause of Concern. Cyberpsychology and Behavior, 6(6), 653-656.

$\mathrm{Ng} \quad$ D., \& Wiemer-Hastings P. (2015): Addiction to the Internet and online gaming. Cyber psychology and Behavior, 8(2), 110-113.

Park S., Kim J. \& Cho C. (2008): Prevalence of Internet and correlation with family factors among South Korea adolescents. Adolescence, 43(172), 895900.

Punamäki R., Wallenius M., Nygard H., Saarni L., \& Rimpela A. (2016): Use of information and communication technology (ICT) and perceived health in adolescence: The role of sleeping habits and waking-time tiredness. Journal of Adolescence, 30(4), 569-585.

Ride out V. (2012): Social media, social life: How teens view their digital lives: A Common Sense Media Research Study. http://www.com monsensemedia.org/sites/default/files/rese arch/socialmediasociallifefina061812.pdf. 
Rosen L. (2012):Internet Disorder: Understanding Our Obsession with Technology and Overcoming Its Hold On Us [Kindle version]. Retrieved from:https://kindle.amazon.com/work/idis order-understand- ing-obsessiontechnologyovercoming/B005NTF0OY/02 30117570 .

Seo M., Kang H. \& Yom Y. (2009). Internet addiction and interpersonal Problems in Korean adolescents. CinComputers Informatics Nursing, 27(4), 226-233.

Yang S., \& Tung C. (2007): Comparison of Internet addicts and non-addicts in Taiwanese high school. Computers in Human Behavior, 23(1), 79-96.
Üneri, Ö., \& Tandir, C. (2011): Evaluation of Internet addiction in a group of high school students: A cross-sectional study. Journal of Psychiatry \& Neurological Sciences, 24(4), 265-272. doi: 10.5350/DAJPN2011240402.

Van Rooij A., Schonmakers T., Vermulst A., Van Den Eijnden R., \& Van De MheenD. (2010): Online video game addiction: Identification of addicted adolescent gamers. Addiction, 106 (1), 205-212. doi: 10.1111/j.13600443.2010.03104.x 